\title{
Versatile Electron Lenses: New Accelerator "Swiss Knife"
}

\section{Vladimir SHILTSEV (Fermilab)}

2019 International Particle Accelerator Conference

23 May 2019 - Melbourne, Australia 


\section{Tetsuji \\ NISHIKAWA (1926-2010)}

- 1964-66 BNL linac

- 1969 Japan National Lab for High Energy Physics

- $12 \mathrm{GeV}$ proton synchrotron

- Neutron facility ( $\rightarrow \mathrm{J}$ PARC)

- $500 \mathrm{MeV}$ cancer treatment synchrotron

- KEK Photon Factory

- TRISTAN collider 
Many thanks to those who nominated me and many colleagues I had fortune to work with over many years on the electron lenses, the Tevatron collider and many interesting and important topics from beam-beam effects to bent crystal collimation, ground motion and orbit stabilization, head-tail instability and super-fast HV pulsers, future collider designs and construction of IOTA ring, beam commissioning of the worlds' best ILC CryoModule and very fast cycling HTS magnet. 


\section{What Can Be Done With Electron Space Charge}

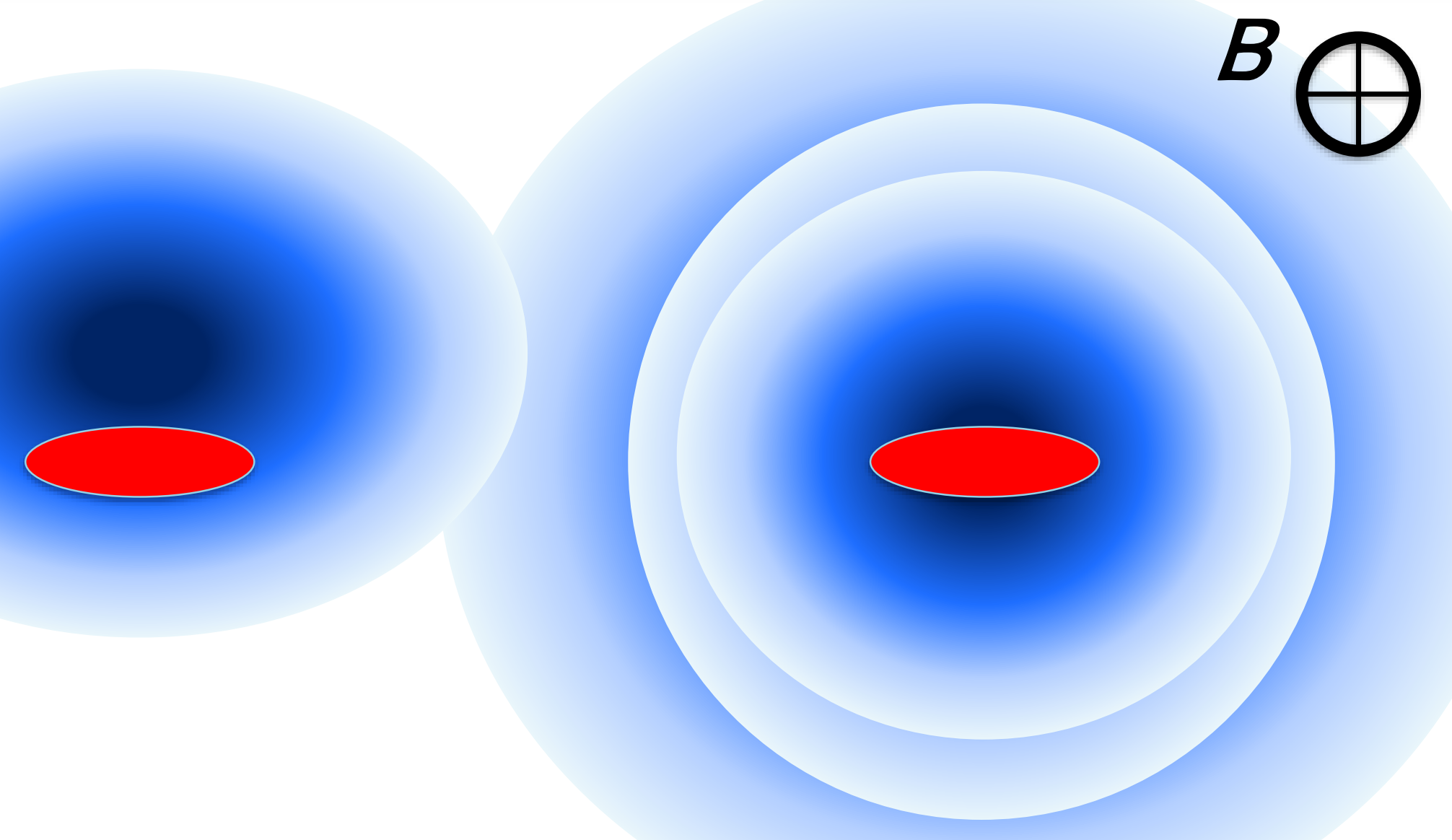




\section{Electron Lens}

$\sim 4 \mathrm{~mm}$ dia $2 \mathrm{~m}$ long in 3T solenoid beam of $.0 .9 \mathrm{kV}$ $\sim$ A electrons $\left(\sim 10^{12}\right)$ can turn on/off ip.

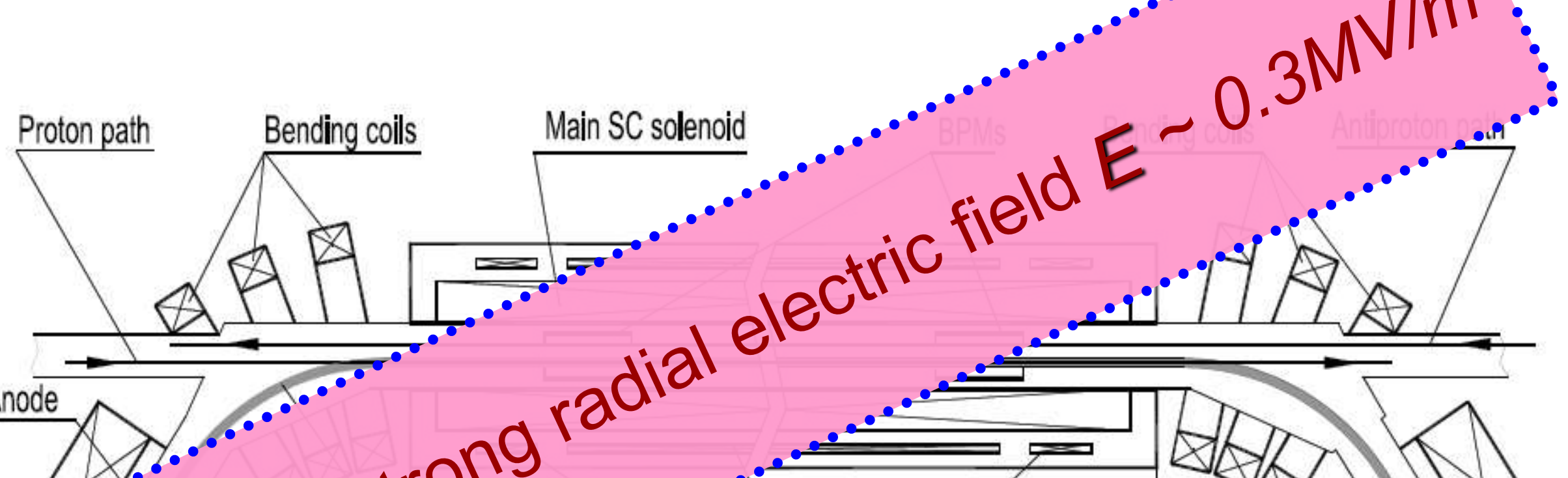
Anode

1.0 .0 .0 strong

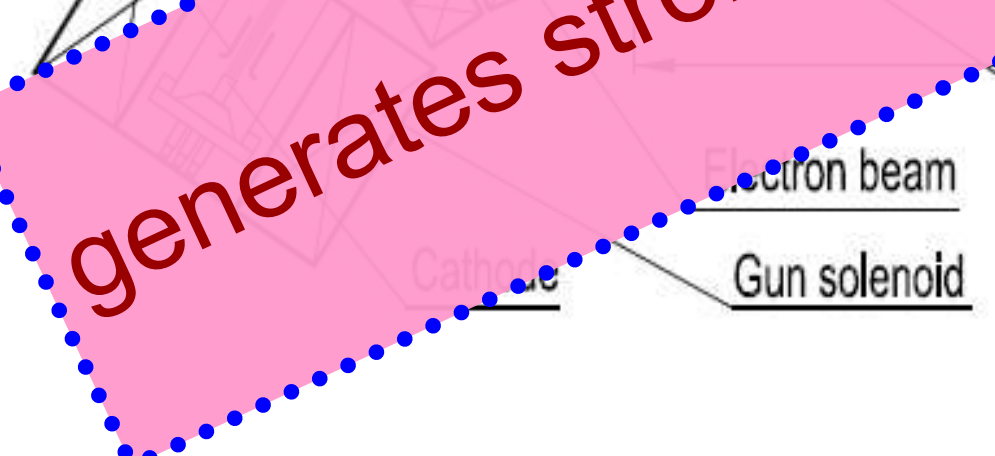

Dipole corrector cols Collector solenoid 


\section{Two Electron Lenses Were Installed in Tevatron}

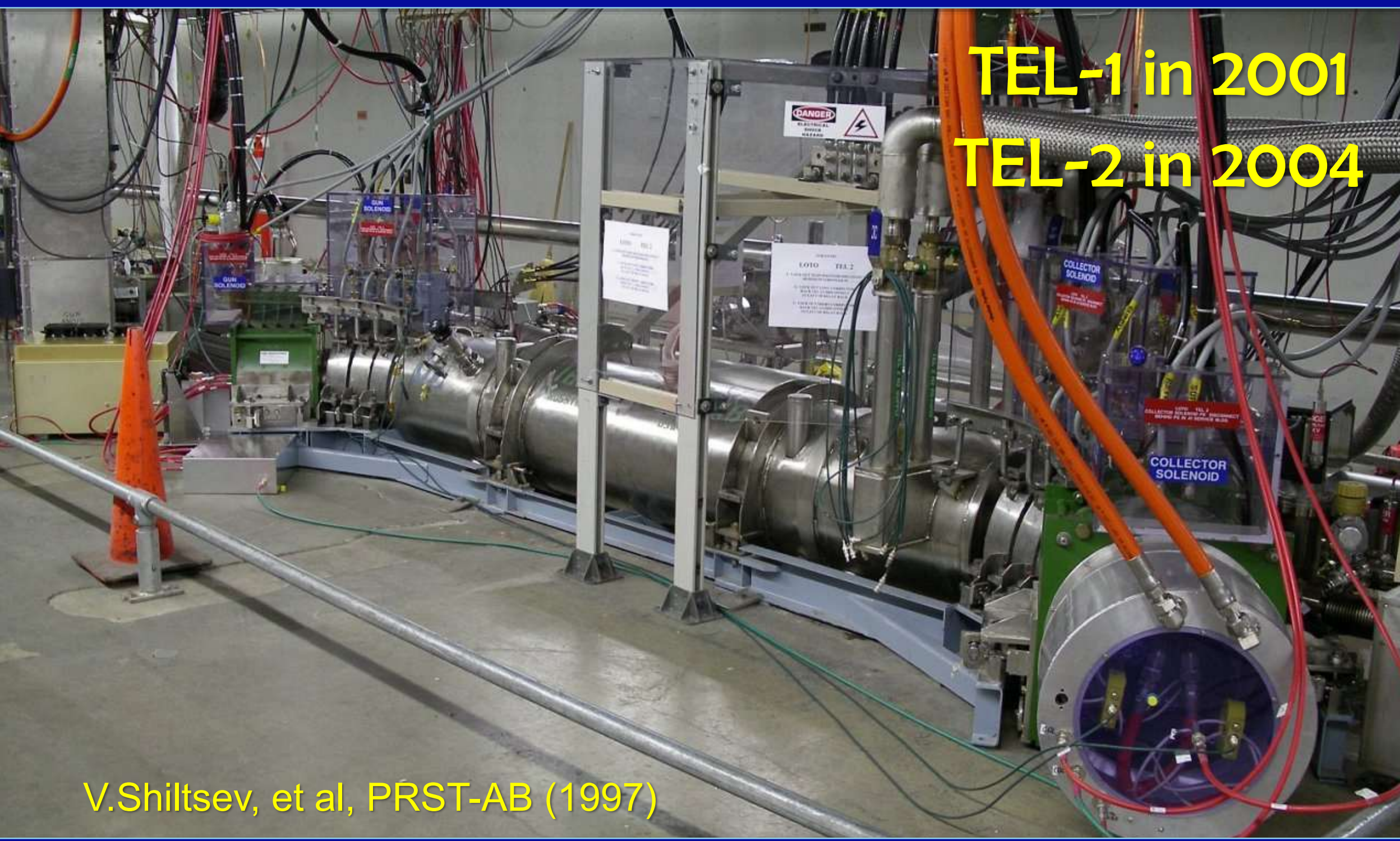




\section{What Electron Lenses Are Good For (1)}

\section{In the Fermilab Tevatron Collider:}

* long-range beam-beam compensation (varied tune shift of individual $1 \mathrm{TeV}$ bunches by 0.003-0.01);

Shiltsev et al., Phys. Rev. Lett. 99, 244801 (2007)

* abort gap collimation (for years in regular operation);

Zhang et al., Phys. Rev. ST Accel. Beams 11, 051002 (2008)

* studies of head-on beam-beam compensation;

Shiltsev et al, NJP (2008); Stancari et al., PRL 107, 084802 (2011)

* demonstration of halo scraping with hollow electron beams;

Shiltsev (2006); Stancari et al., Phys. Rev. Lett. 107, 084802 (2011) 


\section{What Electron Lenses Are Good For (2)}

\section{Presently used in RHIC at BNL for head-on beam-beam}

compensation with significant luminosity gain $\sim \times 2$ Fischer et al., Phys. Rev. Lett. 115, 264801 (2015)

\section{Current areas of research:}

$>$ hollow electron beam collimation of protons in the HL-LHC;

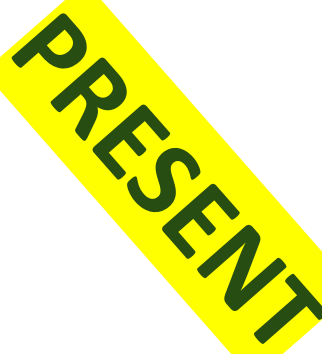

Conceptional Design Report, CERN-ACC-2014-0248 (2014)

$>$ long-range beam-beam compensation as current-bearing "wires" in the HL-LHC

Valishev,Stancari, arXiv:1312.5006; Fartoukh et al., PRSTAB 18, 121001 $>$ generation of nonlinear integrable lattices, eg in IOTA

Shiltsev et al, PRSTAB(1997), Nagaitsev, et al., IPAC'12; Stancari et al., IPh $>$ to generate tune spread for Landau damping of instabilities before collisions in the LHC, FCC-hh (>10,000 octupoles), FNAL Recycler

Shiltsev (2006), Shiltsev, Alexahin, Burov, Valishev PRL (2018)

$>$ to compensate space-charge effects in modern RCSs

Burov, Foster, Shiltsev (2000), Stern et al, IPAC'18 


\section{Book}

Below I present just one example of compensation of space-charge effects by electron lenses

Partide Acceleration and Detection

Vladimir Shiltsev

Electron

Lenses for

Super-

Colliders

r, across the beam

QSpringer

PIC simulations by E.Stern, et al (FNAL) 


\section{Turns in a Ring with $d Q_{S C}=-0.9$}

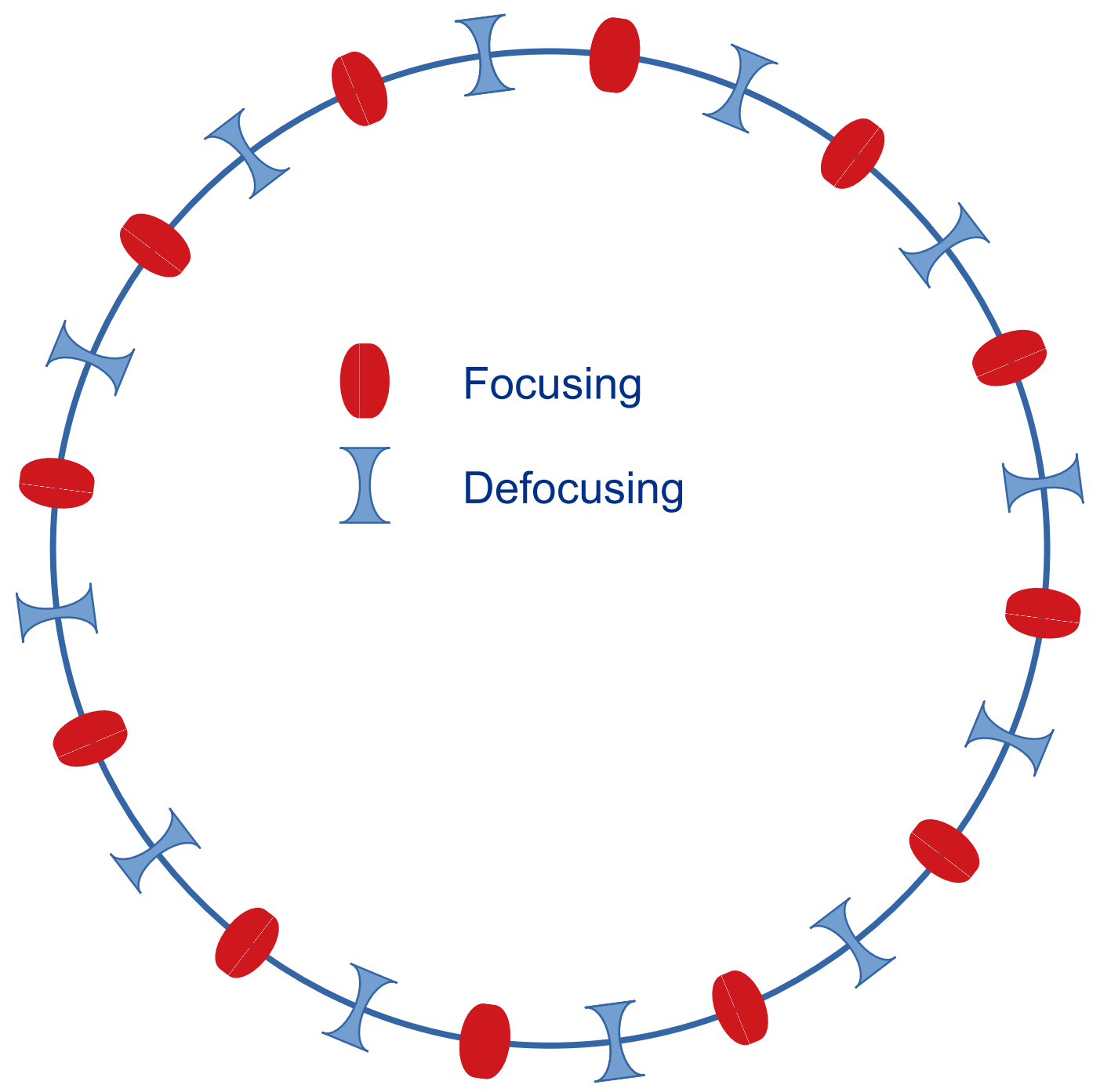

Case \#1 


\section{Turns in a Ring with $d Q_{S C}=-0.9$}

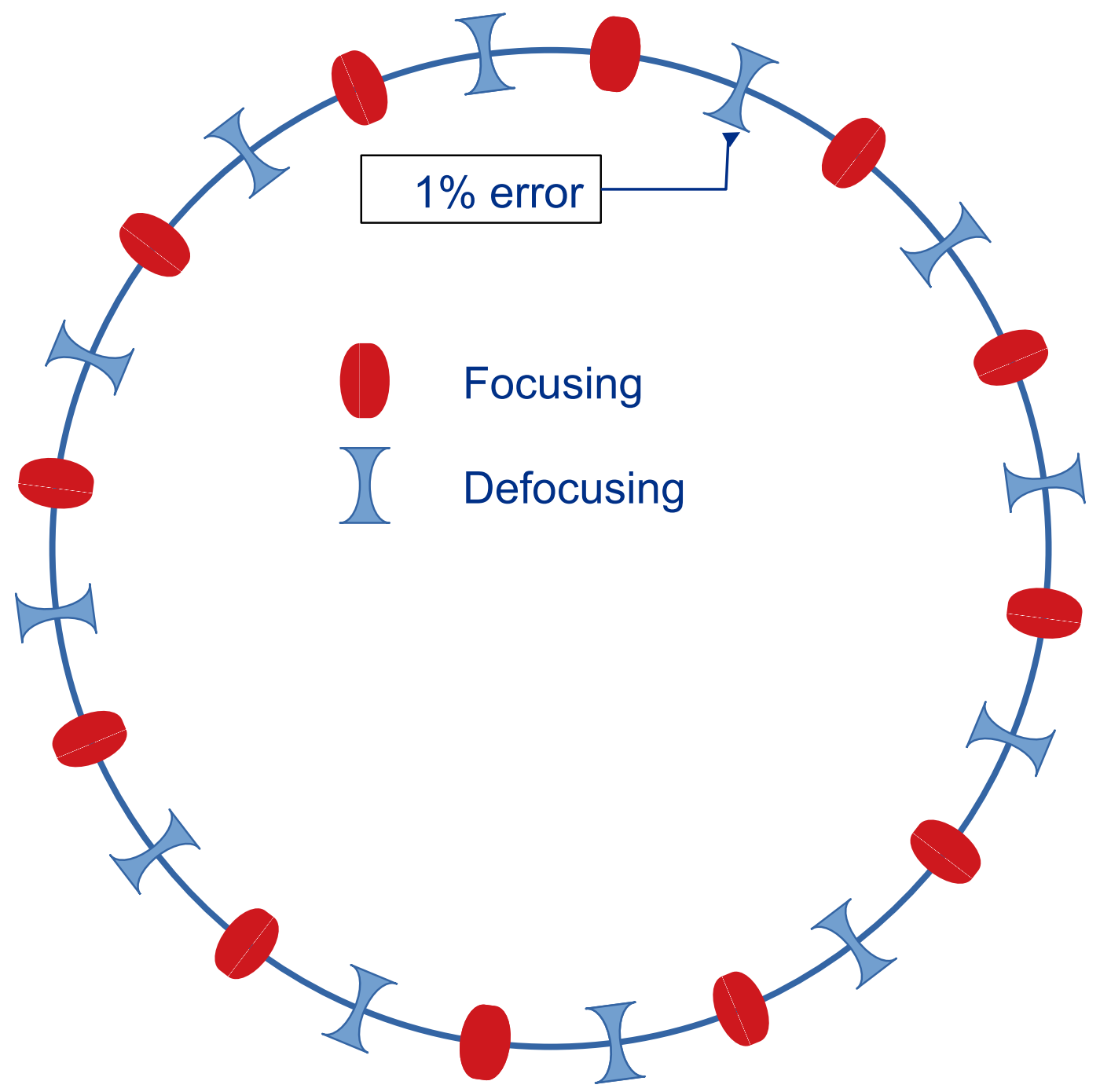

Case \#2 


\section{Turns in a Ring with $d Q_{S C}=-0.9$}

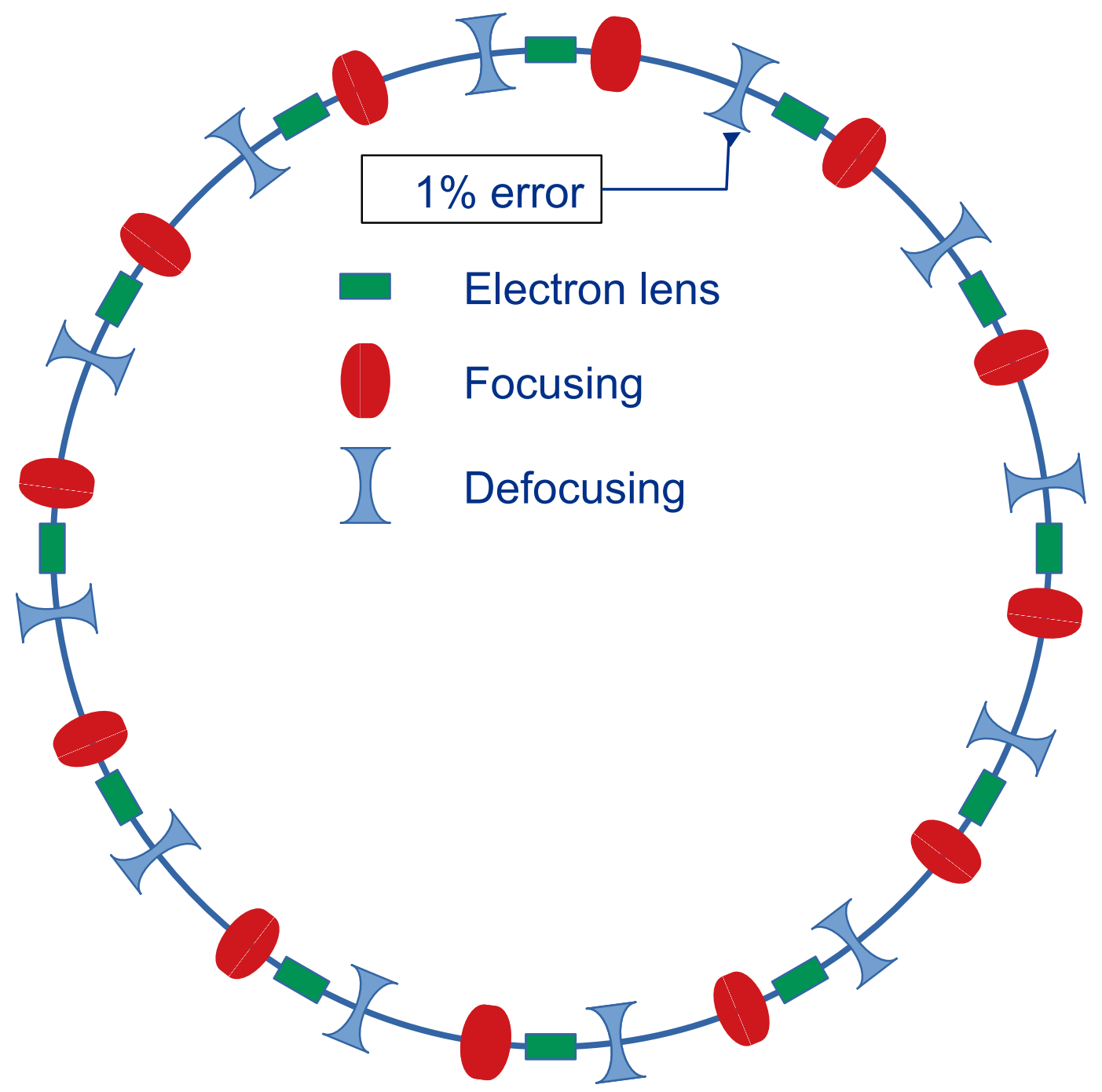

Case \#3 


\section{Tune Footprint $\mathrm{dQ}_{\mathrm{SC}}=-0.9$}

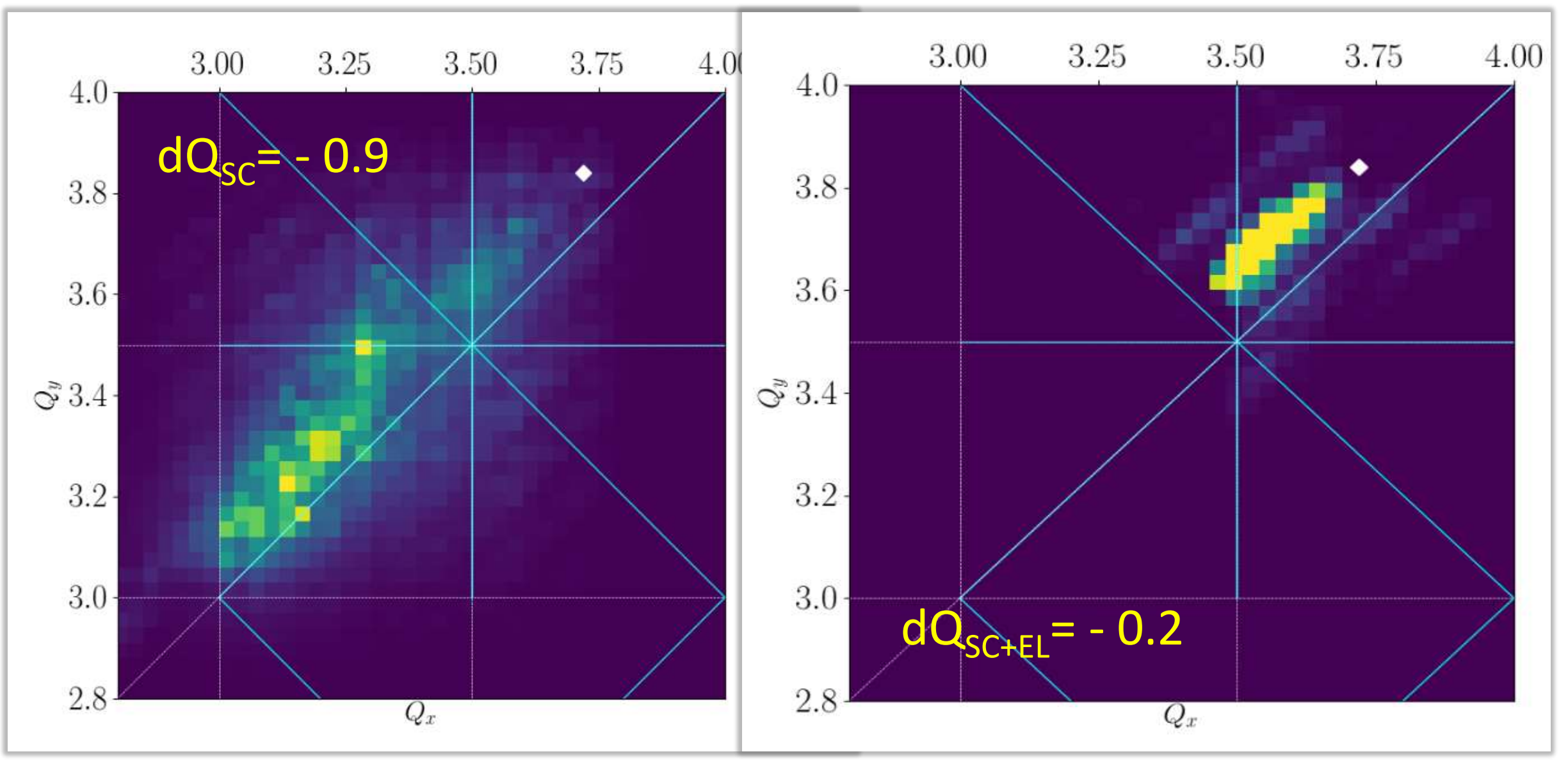

no e-lenses

$\sim 75 \%$ e-lens compensation

Stern et al, THPAF075, IPAC18, Beams Document 6790-v1 FNAL (2019) 


\section{Emittance Growth - Case \#1}

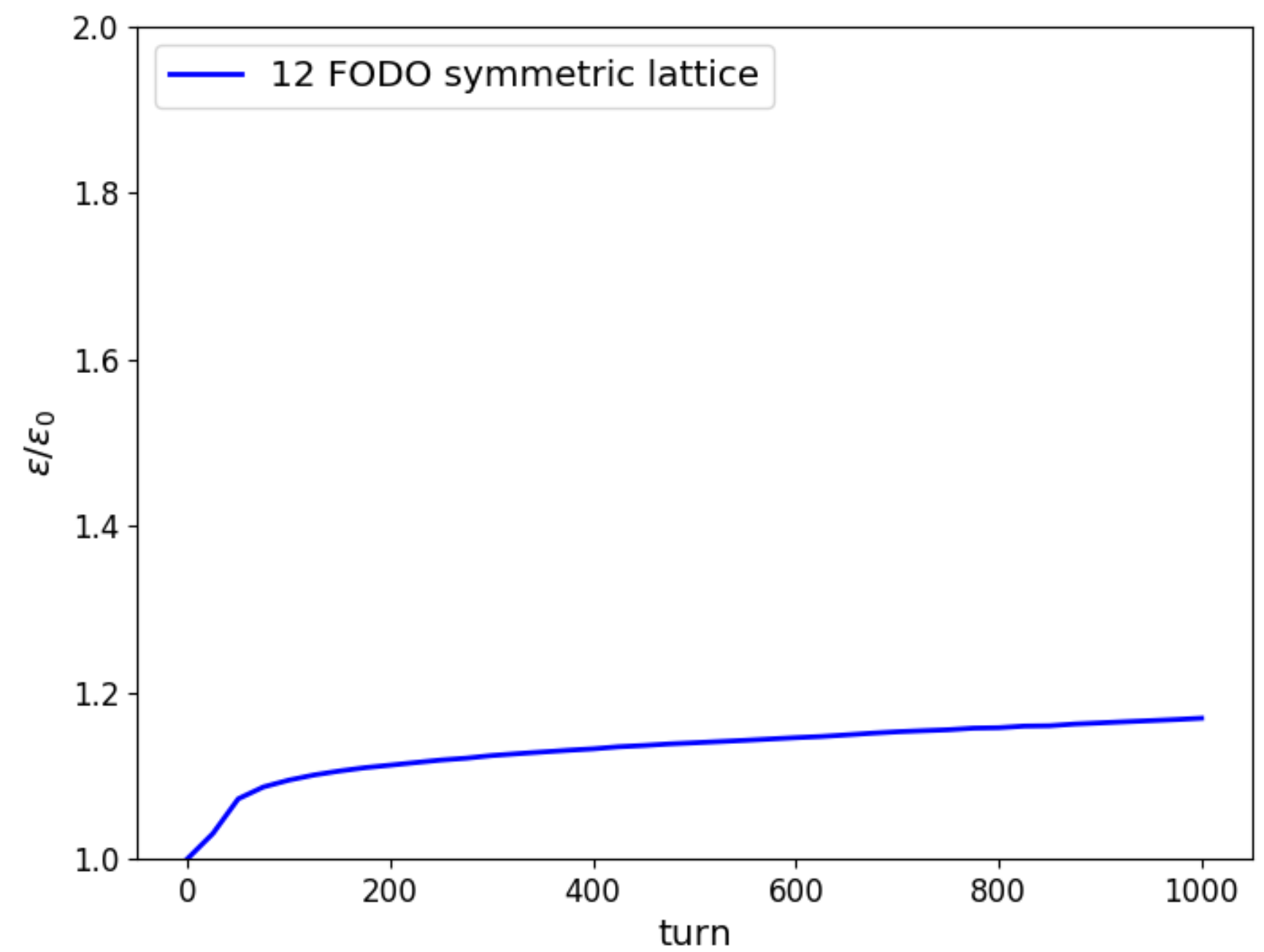




\section{Emittance Growth - Case \#2}

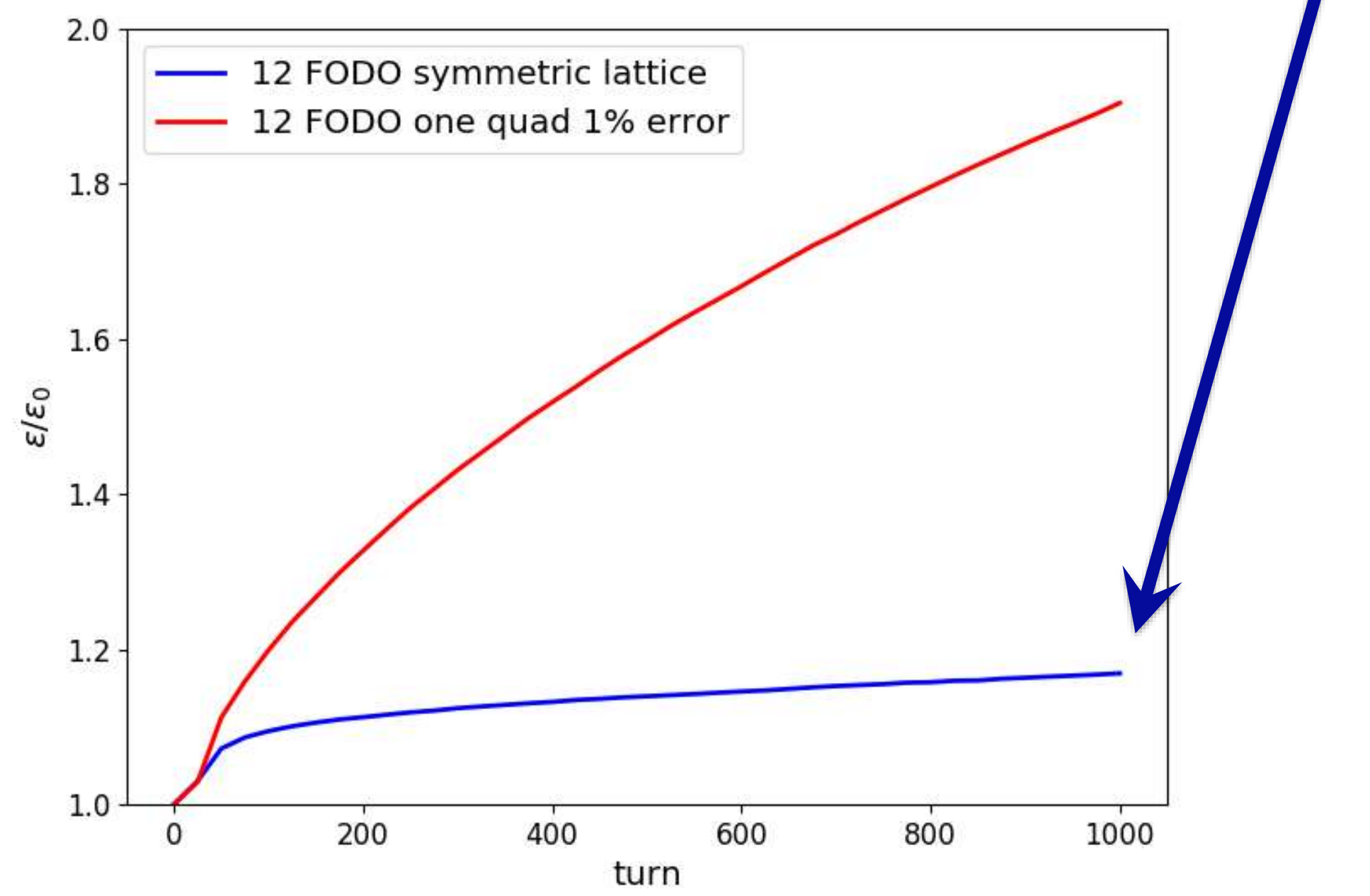

学 Earmilah 


\section{Emittance Growth - Case \#3}

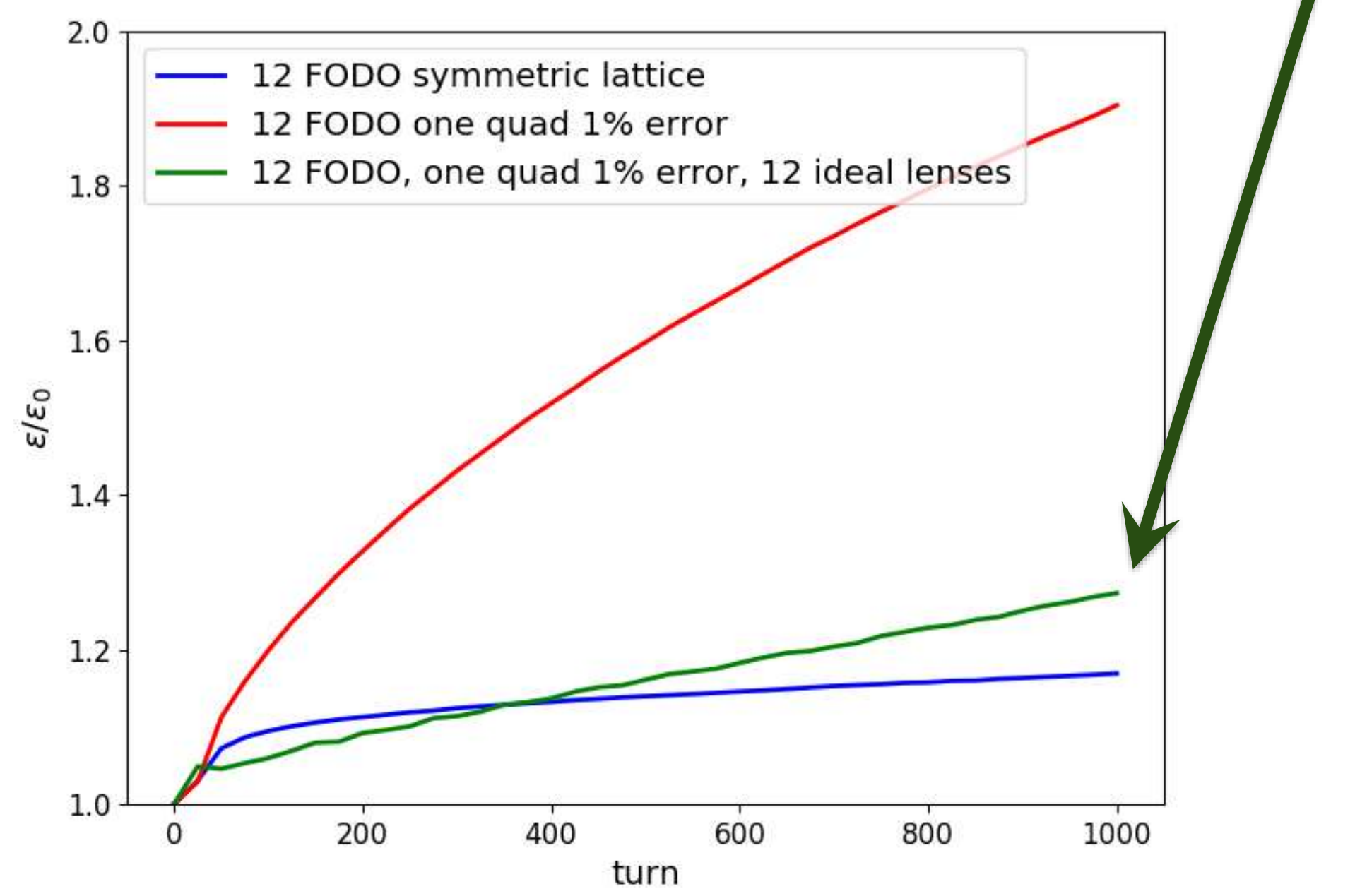

学 Earmilah 


\section{Particle Losses at $4 \sigma-$ Case \#2 and \#3}

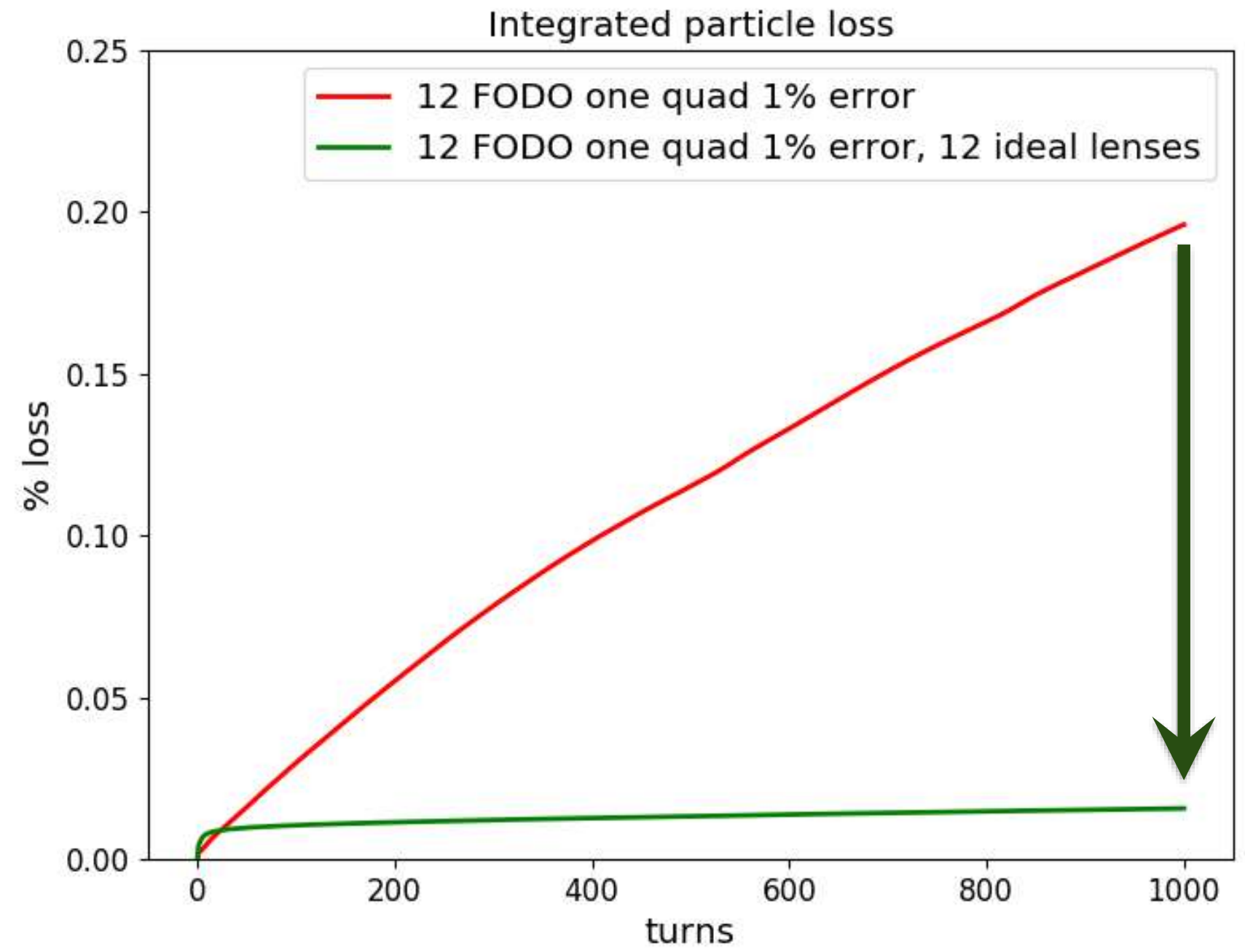

e-lenses reduce losses $\sim 6$ fold! 


\section{Optimal Compensation $\sim 75 \%$ (emitt. growth)}

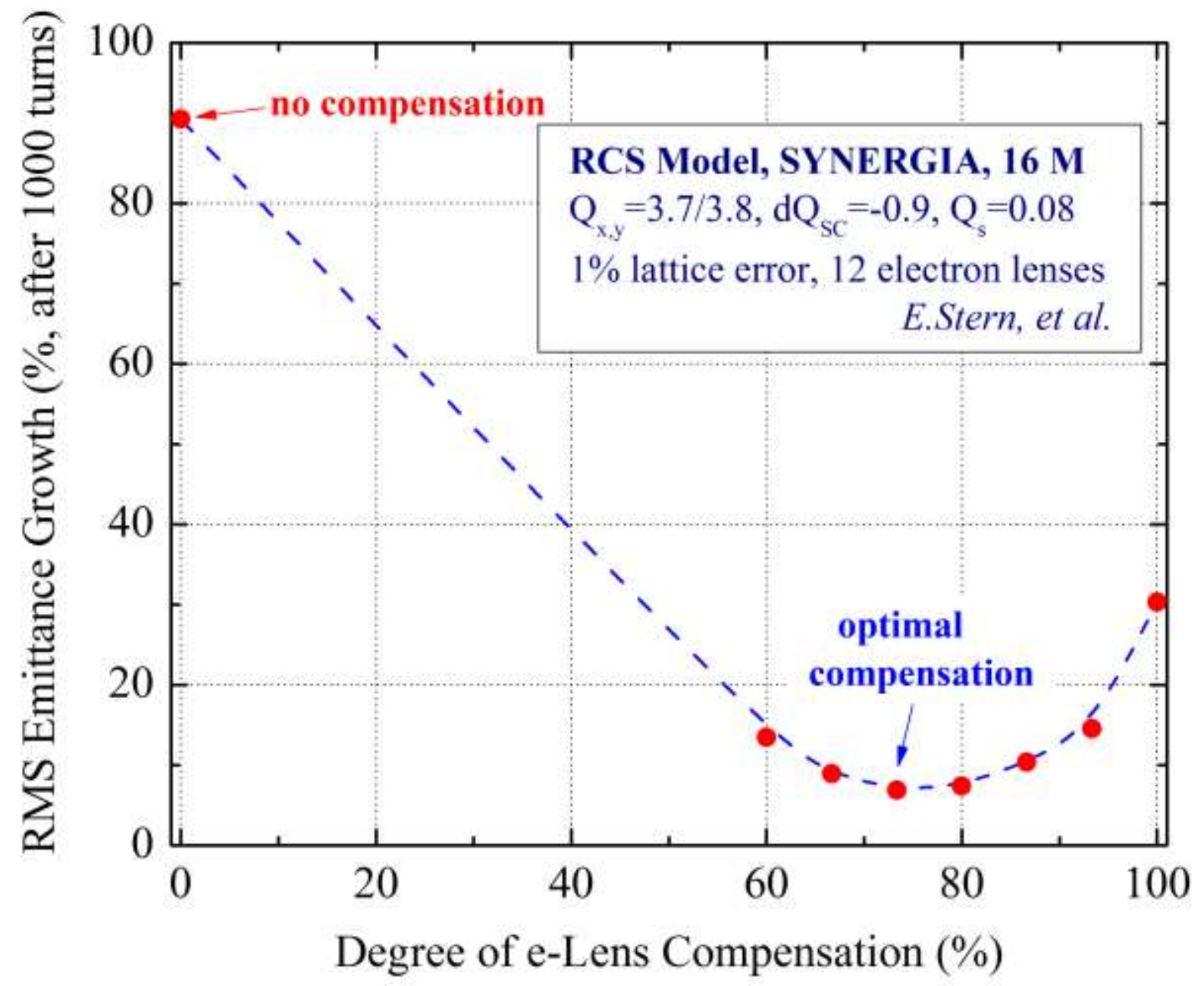

milah 


\section{Optimal Compensation $\sim 70 \%$ (beam losses)}

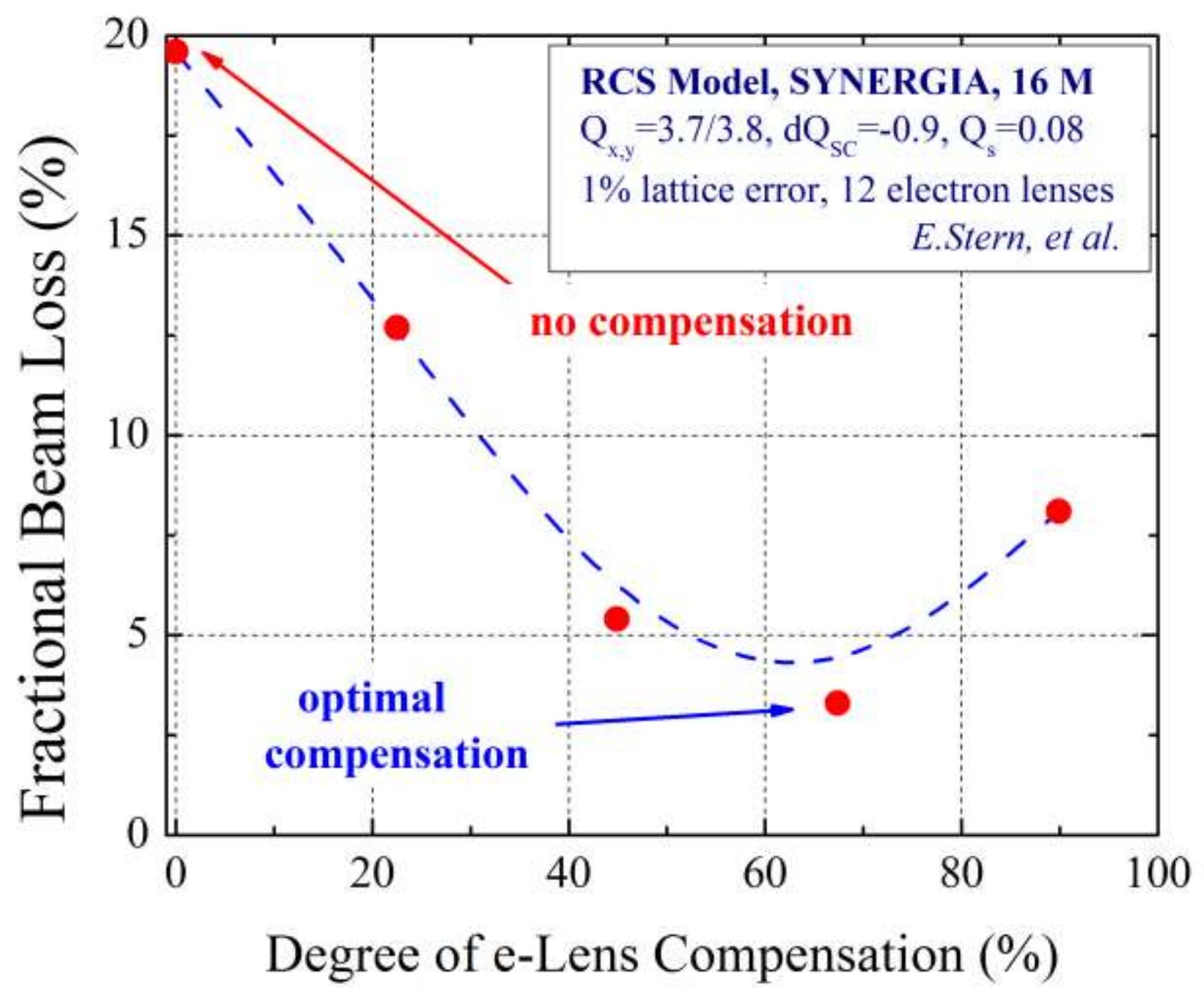

milah 


\section{IOTA: Integrable Optics Test Accelerator}

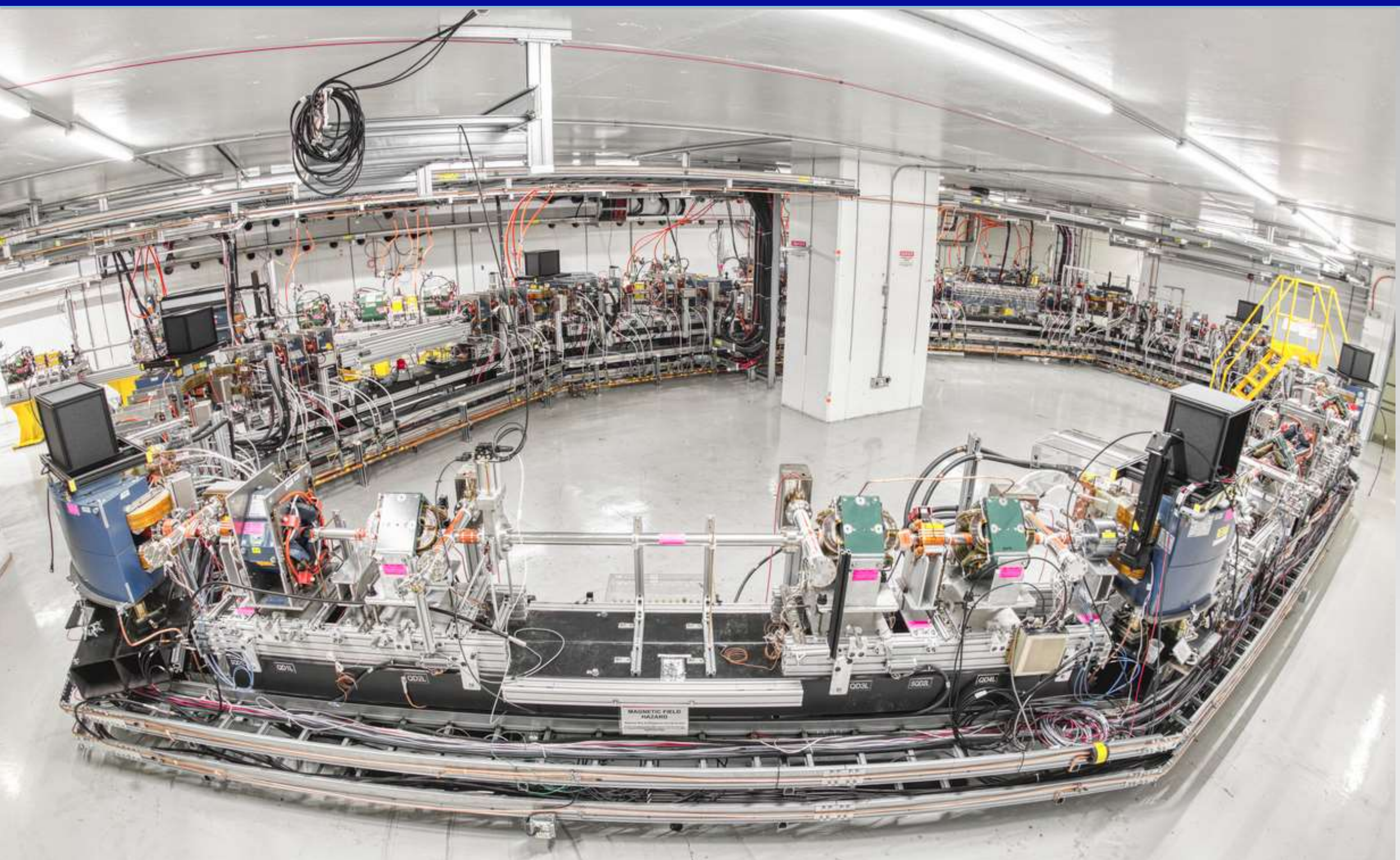




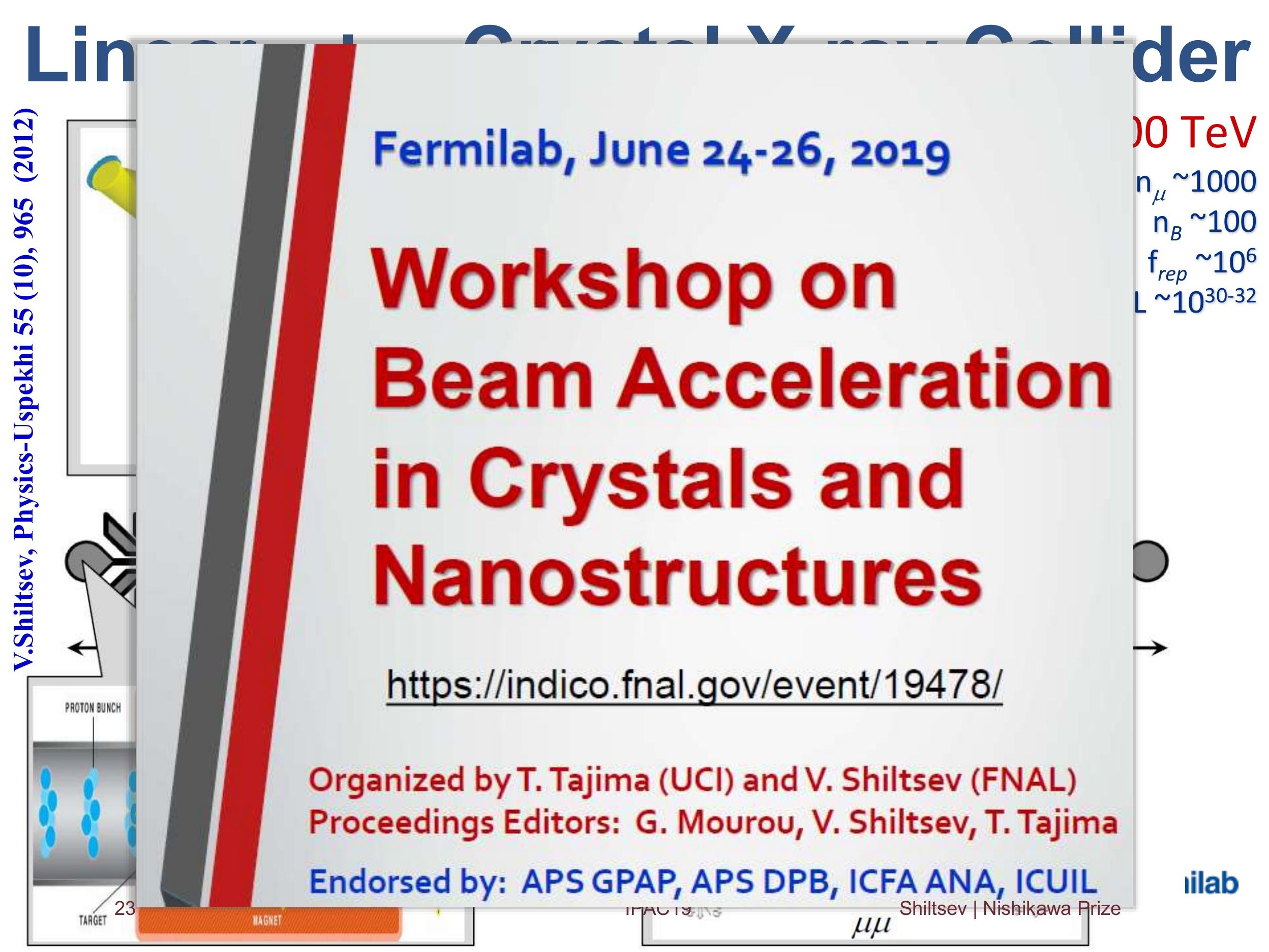


APS Division of Physics of Beams (DPB) is the world's largest and oldest (est. 1985) professional association of accelerator physicists and engineers. The DPB is a highly respected, international organization, open to all with interest in the science, technology and applications of accelerators.

Join us to strengthen the prestige and professional standing of accelerator physics and influence its future development! To learn more and sign up - please, see the American Physical Society (APS) table at this Conference or go to our Web site:

\section{https://www.aps.org/units/dpb/}
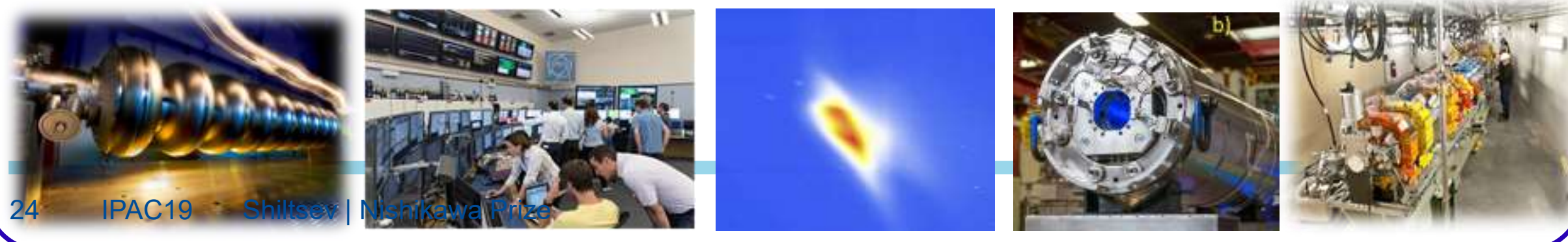


\section{Celebrate Science! - 2019 is UNESCO Int'l Year of Periodic Table (150 ${ }^{\text {yrs }}$ )}
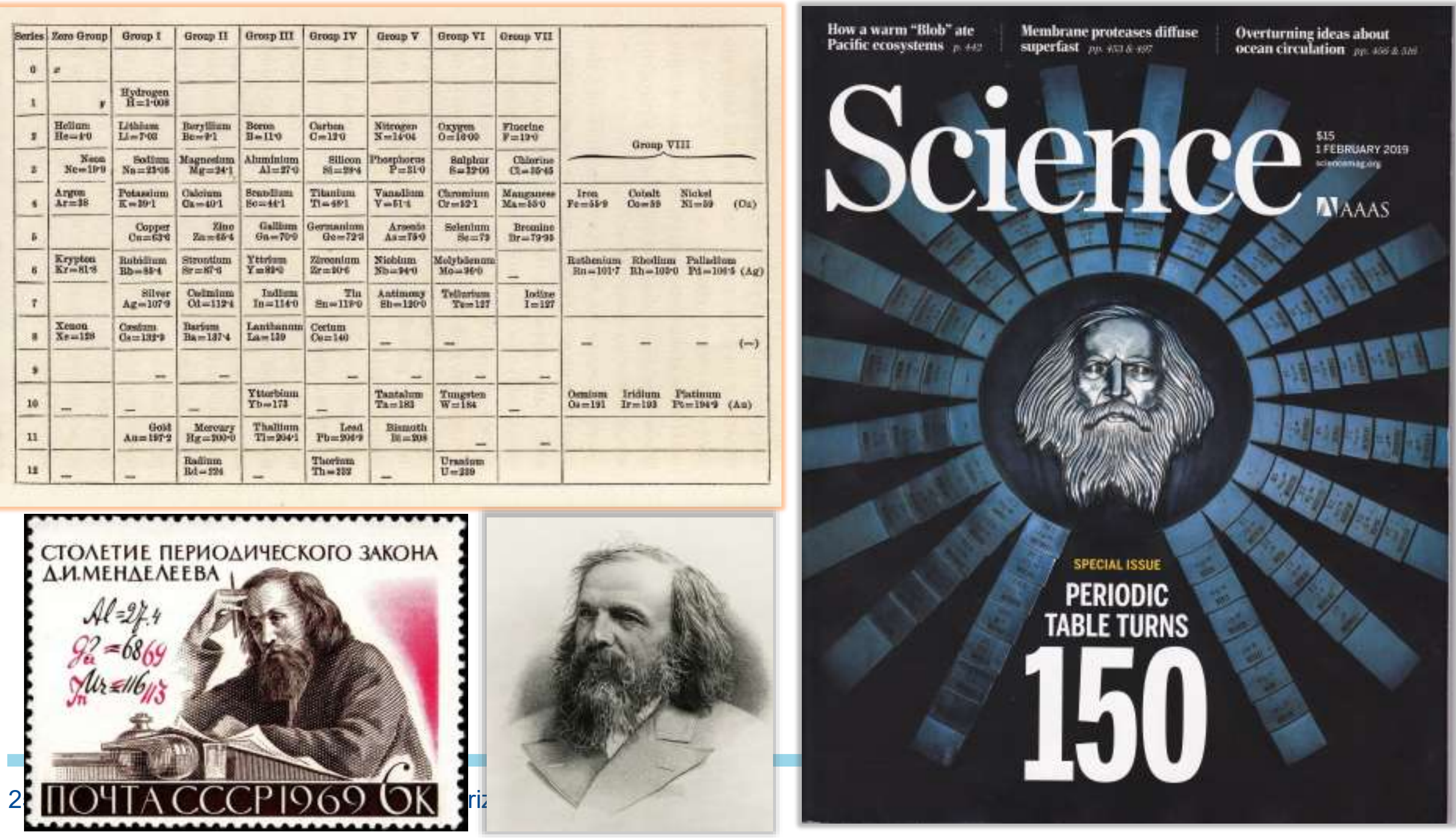


\section{BACK UP SLIDES}




\section{Join APS}

Division of Physics of Beams!

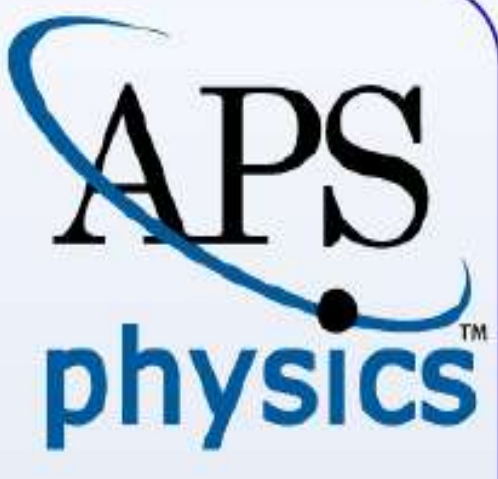

APS Division of Physics of Beams (DPB) is the world's largest and oldest (est. 1985) professional association of accelerator physicists and engineers. The DPB is a highly respected, international organization, open to all with interest in the science, technology and applications of accelerators.

Join us to strengthen the stature and the professional standing of accelerator physics and to influence its future developments! To learn more and sign up - please, see the American Physical Society (APS) table at this Conference or go to our website: https://www.aps.org/units/dpb 


\section{Beam-Beam Compensation}

in Tevatron operation - TELs compensated of long range BB effects
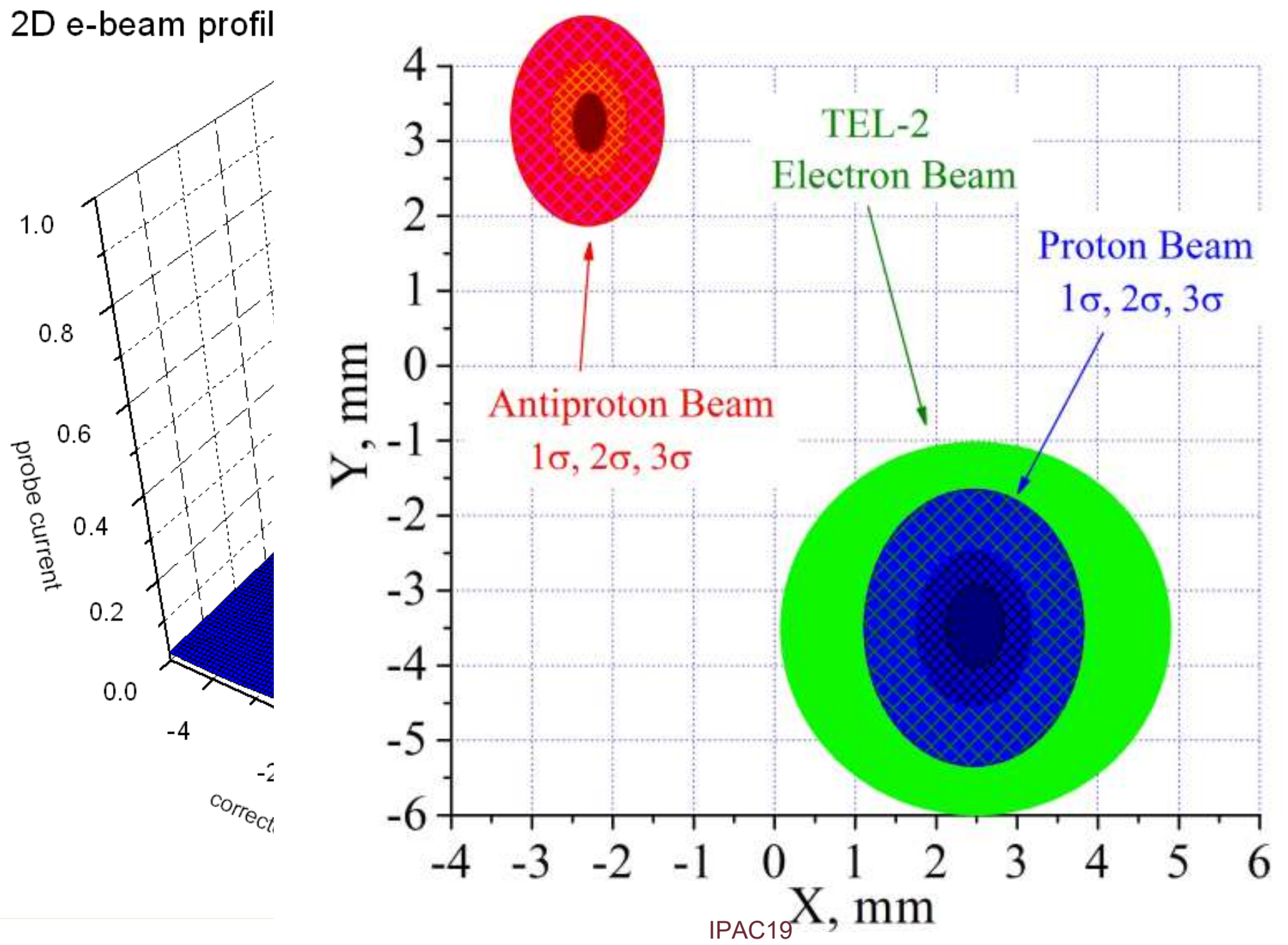


\section{TEL2 on One "Bad" Bunch (P12)}

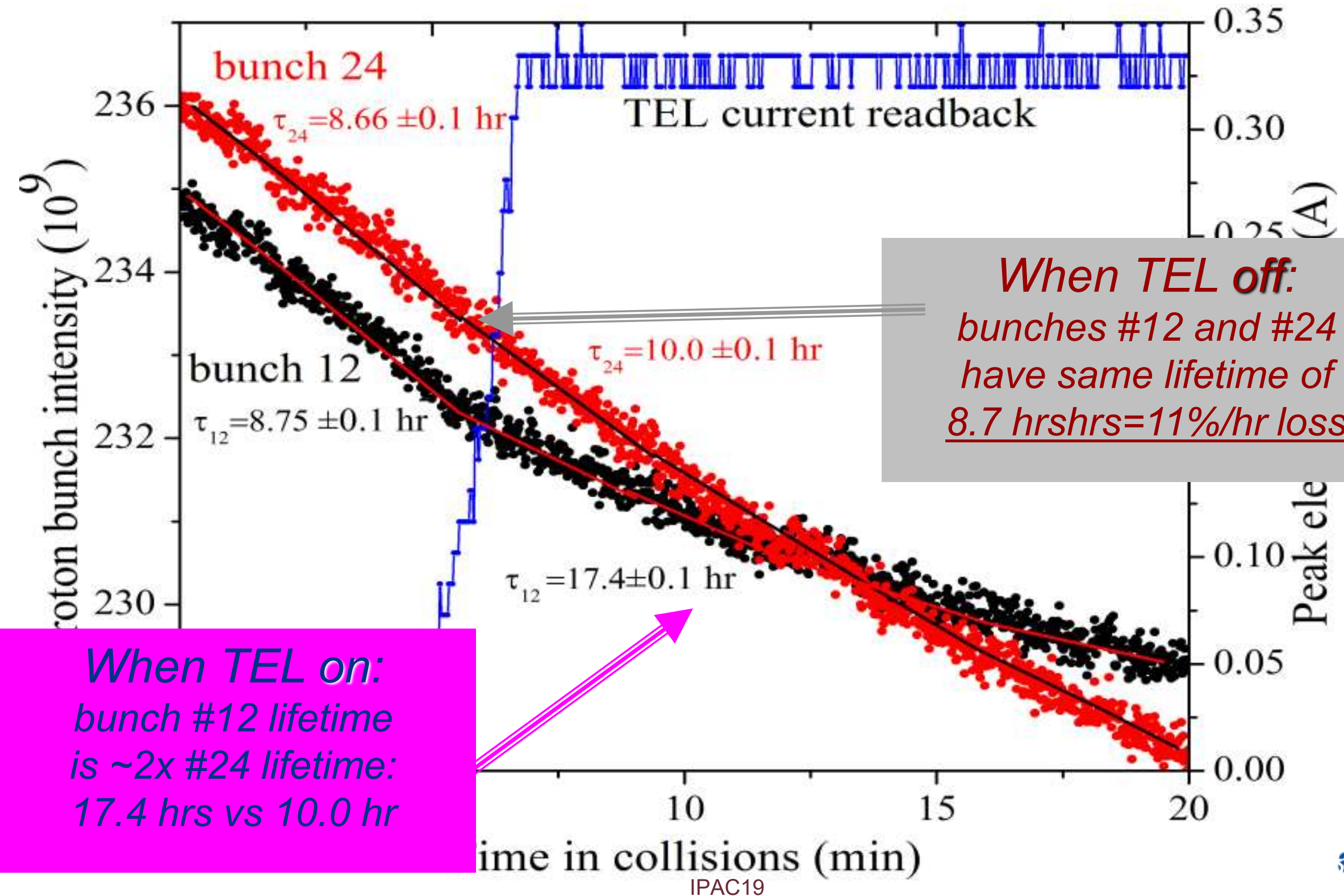




\title{
Physics: Hollow Electron Beam Collimation
}

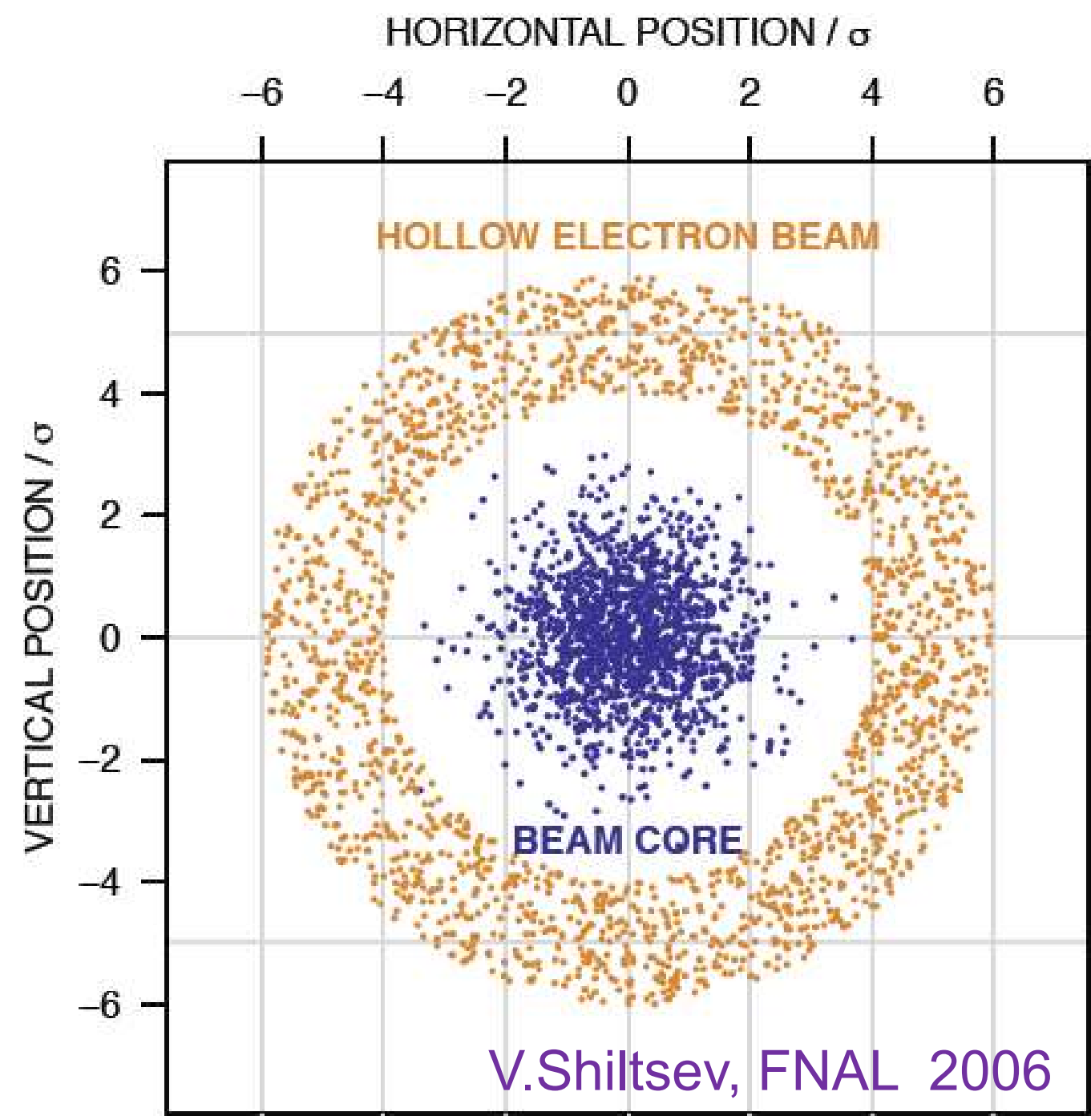

\author{
No EM field inside \\ Strong field outside
}

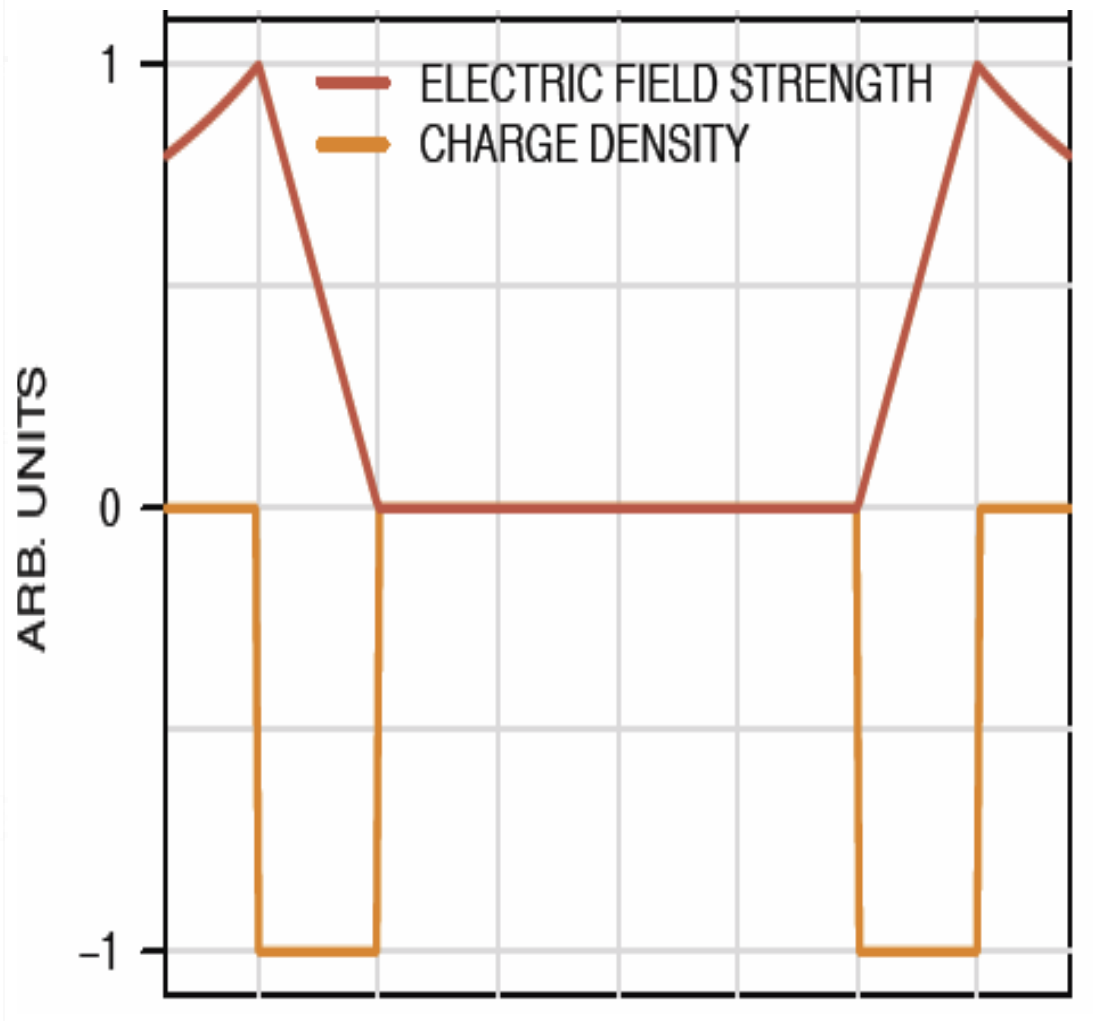




\section{Concept Hollow Electron Beam Collimation}

Tevatron - $2 \mathrm{MJ}$ beams, LHC - $360 \mathrm{MJ}$ beams

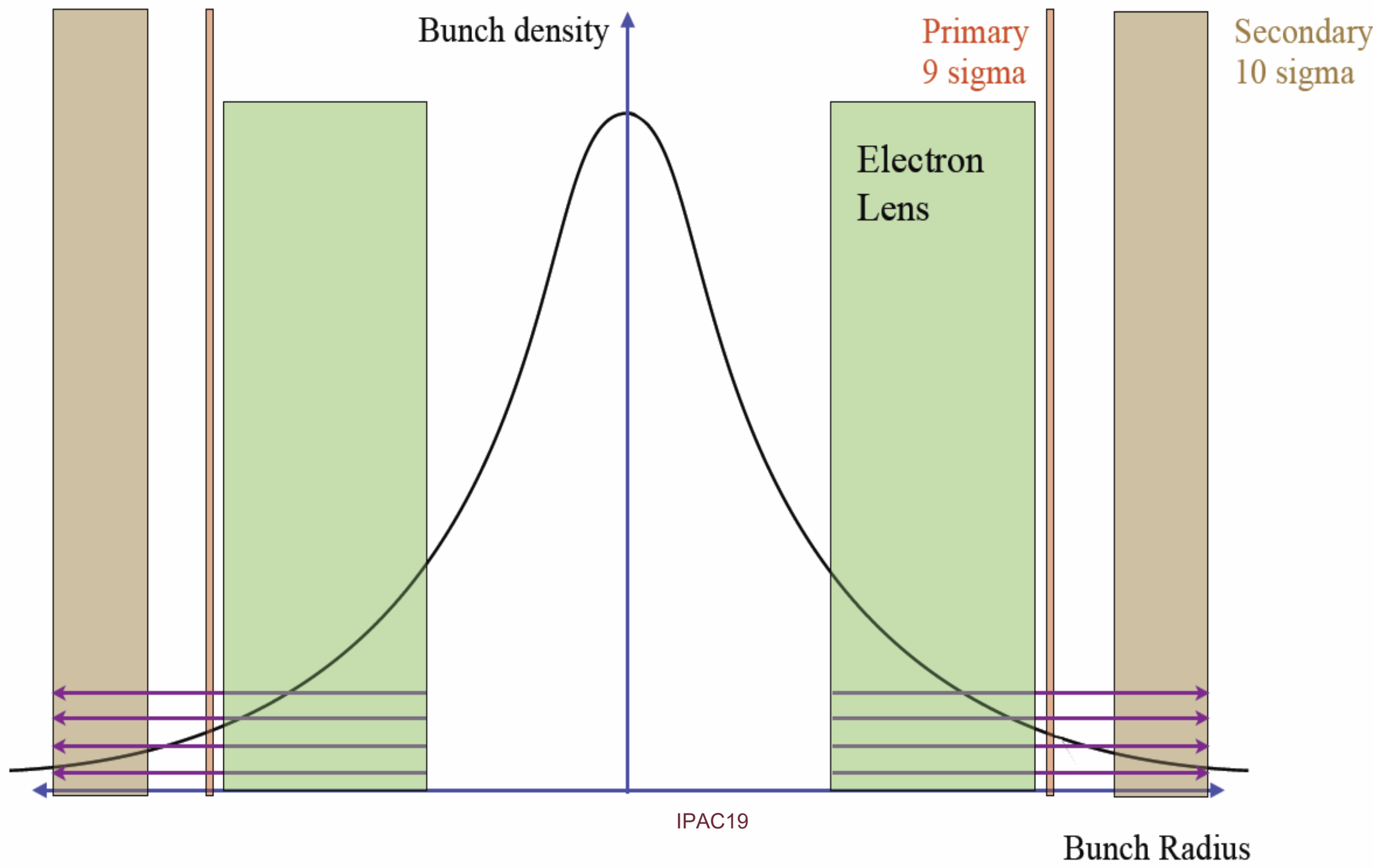




\section{Tevatron Hollow e-Collimator}

\section{Advantages:}

- Kicks are small but not random

- Halo diffusion enhancement

("smooth" scraper)

- Resonant excitation is possible

(pulsed e-beam)

- No material damage

- No ion breakup

e

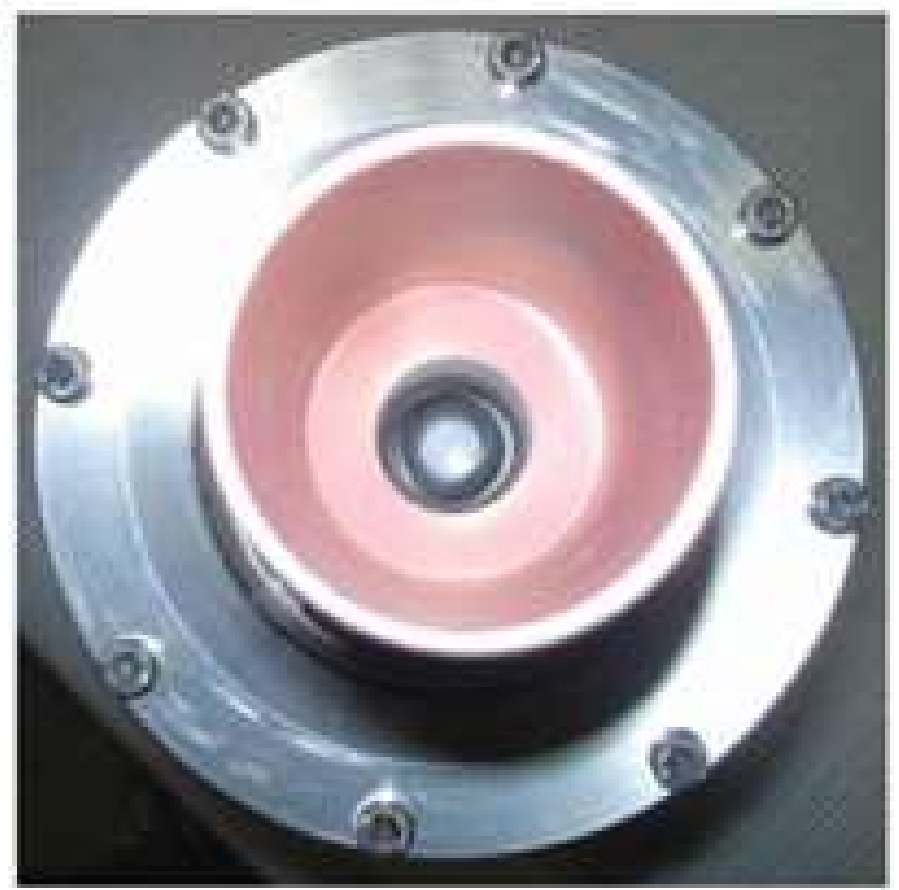

- Low impedance

c

- Position control by magnetic field (no motors or bellows)

- Established e-lens technology

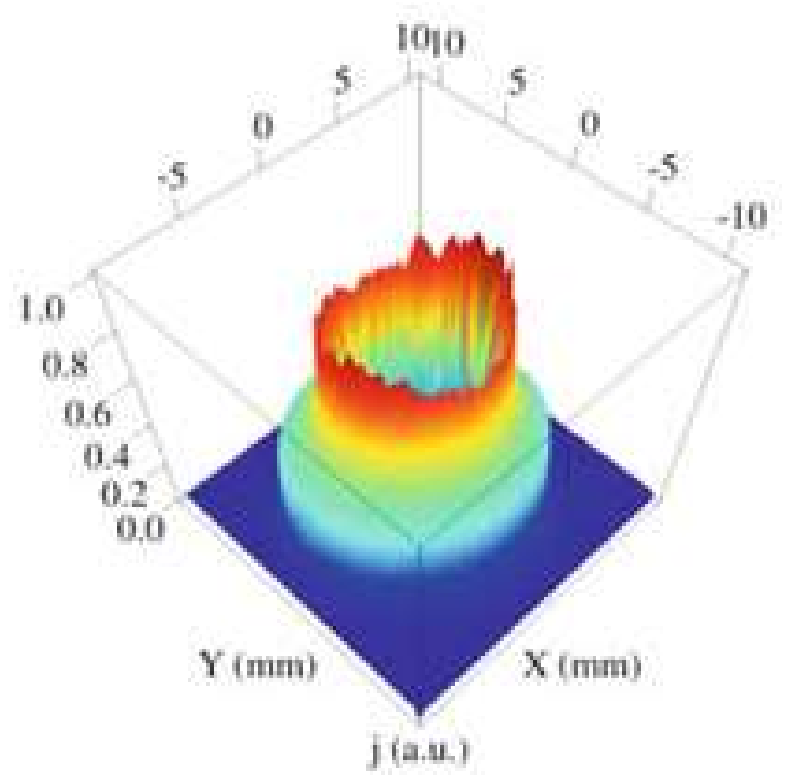




\section{What is an electron lens?}

- DC or pulsed low-energy e-beam

- circulating beam affected by electromagnetic field of e-beam

- e-beam confined and guided by strong solenoids

\section{Perini}

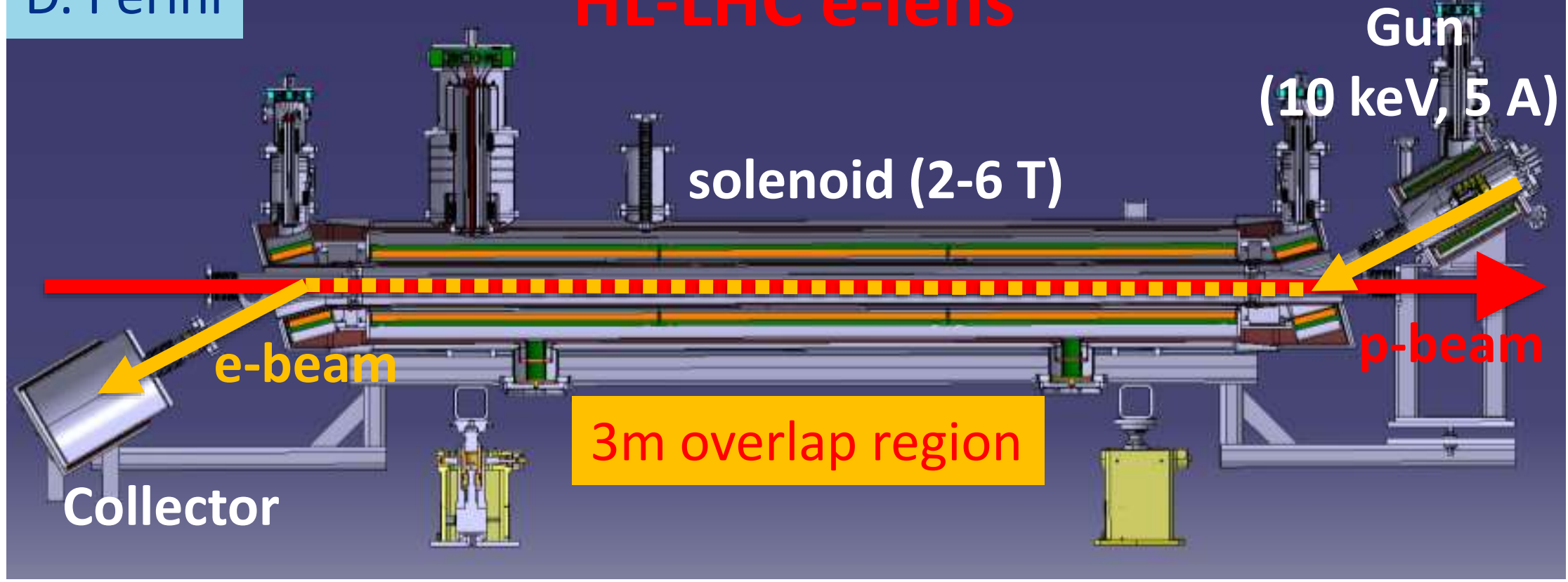




\section{Hollow electron lenses at the LHC}

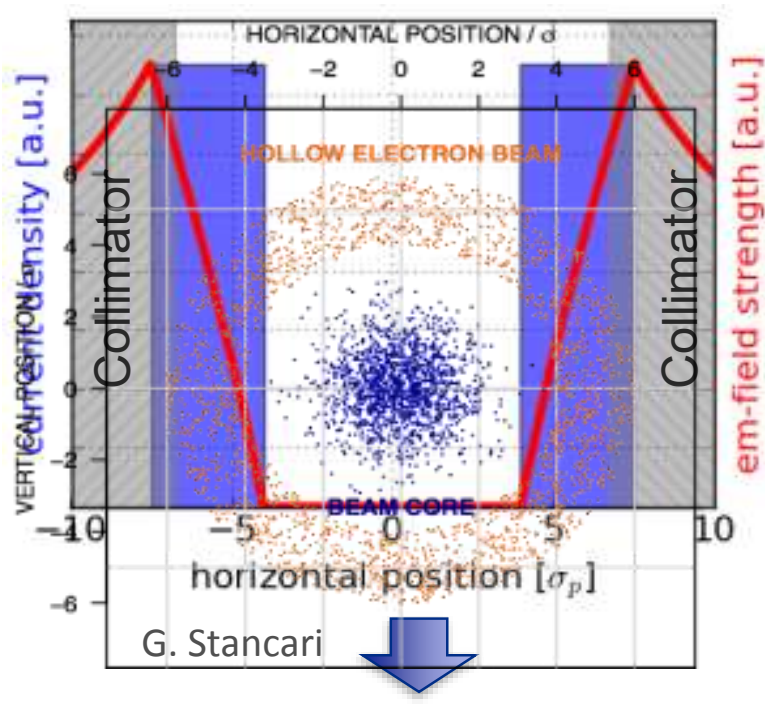

Principle of hollow e-lens:

- increase of diffusion for halo particles

- no effect on core as HEL acts in amplitude space

$\Rightarrow$ active halo control

Modes of operation:

- DC as standard operation mode

$\Rightarrow$ negligible effect on the beam core (to be confirmed)

- pulsed operation to further increase diffusion:

- random current modulation

- $\quad$ switch e-lens on/off every nth turn (drives $\mathrm{n}^{\text {th }}$ order resonances)

$\Rightarrow$ e-lens could introduce noise on the p-beam core 